\title{
Primary Peritoneal Carcinoma
}

National Cancer Institute

\section{Source}

National Cancer Institute. Primary Peritoneal Carcinoma. NCI Thesaurus. Code C40022.

A rare carcinoma that arises from the peritoneum and resembles the malignant surface epithelial-stromal tumors that arise from the ovary. Serous adenocarcinoma is the most common histologic variant. It affects women almost exclusively. The diagnosis of primary peritoneal carcinoma can be made only if both ovaries are not involved by tumor, or, if the ovaries are involved, the tumor is confined to the ovarian surface without invasion of the ovarian stroma and the peritoneal involvement is greater than the ovarian surface involvement. 